municating canine madness, excepting through a lacerafed wound. This notion, however, rested solely on theoretical views in regard to the relative size of the particles of the poison and those of the blood, and is much less to be depended on than the deductions of ancient experience, and inimitable accuracy of observation.

\section{DR. ELLIOTSON AND DR. ROGERS.}

\section{To the Ellitor of THE LANCET.}

Sir :-An advertisement on the cover of your Number for November 3 , introduces my name in a way which seems to demand a little explanation. The most satisfactory way of giving it will be to lay before your readers the following short correspondence. 'The first note is one which, in consequence of the above-mentioned advertisement, I addressed to Dr. Elliotson :-

"Sir:-In The LanceT for last Saturday appears an advertisement, which contains the following passage: - Dr. Elliotson writes thus to the publisher of his lectures:-"A gentleman, of the name of Rogers, dating from Kentish-town, has applied to me for permission to publish ny lectures, which I have refused." We are acquainted with two other gentlemen who have received similar answers.' Will you allow me to ask whether the words of your letter are here transcribed correctly; or, whether they are what the advertiser considers to be your meaning, put into his oun words. The letter which $I$ had the honour of receiving from you hardly seems to bear out that statement. What $I$ nnderstood from the letter was, that while you would not identify yourself with any edition, neither would you oppose it. It is true you expressed an opinion that the lectures were not $u$ orthy of publication; but the rest of the profession think very differently on that subject. I am, Sir, \&c.-November 8, 1838."

The following extracts from the Doctor's reply, are all that it is necessury to trouble you with: - "Dr. Elliotson presents his complinents to Dr. Rogers, and begs to say, that he has no recollection of having written to the effect mentioned. He could not have intended to mean that he had forbidden Dr. Rogers to publish them. Ha could hare meant only, that he declined having anything to do with the publication.-Conduit-street, November 12."

Hoping you will grant me the short space in your columns that this explanation will occupy, I am, Sir, your obedient servant,

$$
\text { N. Rogers, M.D. }
$$

3, Sussex-terrace, - K entish-tawn, December 11, 1838.

\section{UNIVERSITY COLLEGE HOSPITAL.}

DISFASE OF THE WRIST-JOINT.-AMPUTATION.

J. E., aged 63, was admitted Sept.11th, under the care of Mr. Liston; he is of temperate babits, and appears constitutionally healthy. Three months since he first noticed a soft swelling about the left wrist, which lad previously becorne somewhat weakened. The swelling gradually enlarged, in spite $o^{c}$ a succession of applications, consisting of poultices and blisters, iodine and mercurial ointment. Ulceration, unaccompanied with discharge, or bleeding, at the time. The wrist had previousiy been in perfect health, and he recollects no blow, or other cause for the appearance of the tumour.

There is at present a large irregular swelling involving, apparently, the heads of the radius and ulna, and the carpal bones, but not penetrating into the joint, since the motion of pronation and supination are fully, and those of flexion and extension partly, performed without grating, \&c. The tumour is elastic to the feel, and in some places very soft, cspecially upon the thenal aspect, where, at one place, fluctuation is evident. On this surface also are two ulcerated openings, one on the ulnar, the othor on the radial side; they seem to have been more extensive, marks of cicatrisation being evident around them. Their appearance now is nearly healthy, but their edges are raised, and they discharge a thin, curdy fluid. The integument is healthy in its colour at the back of the diseased part; this is the case also in the front, with the exception of a litule reddening round the openings, and at the soft point where fluctuation is felt. The radial and ulnar arteries pulsate just under the integument and above the morbid growth; the veins on the back of the wrist are slightly enlarged as they pass over the tumour. Bowels open; tongue clean; no signs of fungoid disease in any other part. Mr. Liston pierced the integuments at the softest point with a lancet, and gave exit to about an ounce of pus nixed with blool. This proceeding, however, did not either materially diminish the bulk of the tumour or its elasficity to the touch.-Water dress. ings to the wound.

Sept. 17. There has been no further dis. charge from the wound made on the 12th. The part to be strapped with lead plaster and bandaged.

25. The same treatment has been pursued since the last report. The wrist is now diminishing in size; a considerable quan. tity of semi-purulent matter is discharged from the opening.

Oct. 6. Nothing remarkable since last report. To-day, however, there is much inflanmation about the wrist, attended by pain and throbbing, with an erysipelatous blush on the surface; swelling very much 